\title{
Prediction of Multipath Interference for Static GNSS Applications
}

\author{
Yedukondalu Kamatham \\ Professor, CVR College Engineering/ECE Department, Hyderabad, India \\ Email: kyedukondalu@gmail.com
}

\begin{abstract}
Positional accuracy of Global Navigation Satellite System (GNSS) is limited by several error sources like troposphere, ionosphere, instrumental bias, clock, multipath etc. Among these error sources, multipath is quite significant, since it should be dynamically modeled with respect to user GNSS receiver environment. In this paper, multipath error is estimated based on both code and carrier phase measurements using CMC (code minus carrier) technique. It is quantified with experimental static dual frequency Global Positioning System (GPS) receiver data. The time series of multipath data is analyzed with other satellite parameters like elevation and azimuth angles of satellite vehicle (SV). Multipath error is estimated for all SVs and is analyzed for sequential days to predict the multipath error of any $\mathrm{SV}$ during the forthcoming days. The results are very much encouraging and significant in prediction of multipath error for GPS/GNSS static applications such as atmospheric research using GNSS satellites data and during site selection phase for installing base stations for continuous monitoring of satellites' data.
\end{abstract}

Index Terms: GNSS; GPS; Multipath Error; Code minus Carrier technique; Multipath Repeatability

\section{INTRODUCTION}

Multipath is a phenomenon in which, a signal arrives at a receiving antenna via various directions after signal reflection and/ or diffraction interfering with the direct signal. In the receiver, multipath is analyzed relative to the direct signal by various parameters such as: (1) The amplitude of the reflected or indirect signal, (2) Path delay, (3) Amount of phase from the reflected signal and (4) Phase rate [1]. Various methods were proposed to reduce multipath effects such as hardware, software (data processing) and hybrid approaches. Multipath can be estimated by the code and carrier phase differences between L1 and L2 observations [2]. The Global Navigation Satellite System (GNSS) measurements are biased due to several error sources such as ionospheric and tropospheric errors, satellite and receiver clock errors, ephemeris errors, receiver noise etc. In addition to these, the range estimation experiences a problem of multipath leading to inaccurate estimation of user position in navigation applications. Initially the fundamental analysis of GPS code and carrier multipath was reported by Hagerman (1973) [3]. Multipath is very difficult to model due to its user receiver-satellite geometry dependence and its non-correlation even in very close distances. Consequently, it has received great attention in the literature [4-6]. Better understanding of the multipath environment with respect to the elevation of satellite and distance to reflecting objects, is very important for predicting the multipath error for Global Positioning System (GPS) or GNSS static applications such as atmospheric research and also during the site selection phase in installing base stations for either Differential GPS (DGPS) or Local Area Augmentation Systems (LASS). Here, experimental estimation of multipath and its analysis for static applications is presented.

\section{Multipath ERror Estimation}

Direct and indirect signals received at the GPS receiver have phase differences and relative phase offsets, which are proportional to their differences in path lengths. Multipath error can be estimated by using a combination of carrier phase and code measurements. Extensive work on multipath estimation was reported in literature based on carrier phase and code measurements [7].

$M P_{L 1}$ and $M P_{L 2}$ can be quantified and detected using a dual frequency receiver and is given as [8]:

$$
\begin{aligned}
& M P_{L 1} \cong \rho_{L 1}-\frac{9529}{2329} \cdot \phi_{L 1}+\frac{7200}{2329} \cdot \phi_{L 2}+K_{1} \\
& M P_{L 2} \cong \rho_{L 2}-\frac{11858}{2329} \cdot \phi_{L 1}+\frac{9529}{2329} \cdot \phi_{L 2}+K_{2}
\end{aligned}
$$

Where $\rho_{L 1}$ and $\rho_{L 2}$ are pseudo ranges (in meters) on L1 and L2; $\Phi_{L 1}$ and $\Phi_{L 2}$ are carrier phase measurement (in meters). Using Eqs. (1) and (2), the multipath error on $\mathrm{L}_{1}$ and $\mathrm{L}_{2}$ in meters can be estimated for all epochs of dual frequency GPS data. $\mathrm{K}_{1}$ and $\mathrm{K}_{2}$ are functions of unknown integer ambiguities which can be assumed constant [9].

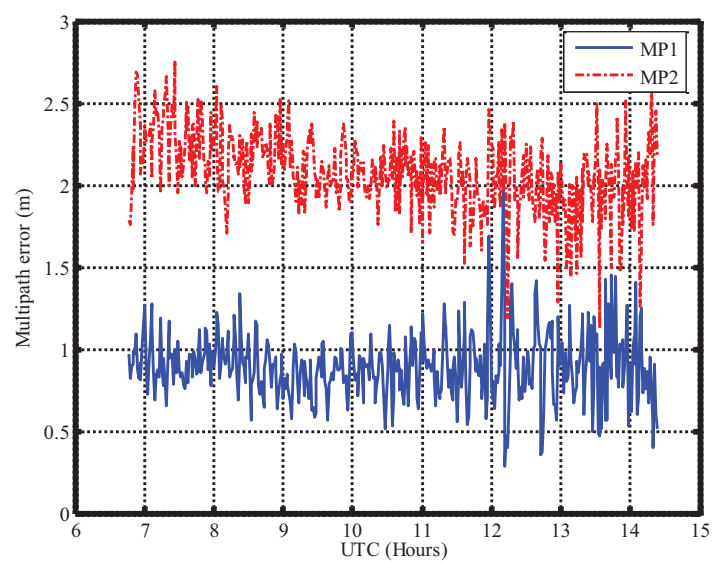

Figure 1. Multipath error on $\mathrm{L}_{1}\left(\mathrm{MP}_{1}\right)$ and $\mathrm{L} 2\left(\mathrm{MP}_{2}\right)$ carrier frequencies

Various experiments were conducted at NERTU (Research \& Training Unit for Navigational Electronics), 
Osmania University (OU), Hyderabad, India, to analyze the effects of multipath for various static stations. For analysis, dual frequency GPS data was recorded on $8^{\text {th }}$ August 2010 at $60 \mathrm{~s}$ intervals. The estimated multipath error for Satellite Vehicle $17(\mathrm{SV} 17)$ on $\mathrm{L}_{1}\left(M P_{1}\right)$ and $\mathrm{L}_{2}\left(M P_{2}\right)$ frequencies is shown in Fig. 1. The mean multipath error on $\mathrm{L}_{1}$ and $\mathrm{L}_{2}$ are $0.79 \mathrm{~m}$ and $2.01 \mathrm{~m}$ respectively. $\mathrm{L}_{1}$ signal consists of $\mathrm{C} / \mathrm{A}$ code and P-code with minimum received power of -160 $\mathrm{dBW}$ and $-163 \mathrm{dBW}$ respectively. But, $\mathrm{L}_{2}$ signal consists of either $\mathrm{C} / \mathrm{A}$ code or P-code $(-166 \mathrm{dBW})$. i.e., $\mathrm{L}_{1}$ signal's power is $3 \mathrm{~dB}$ more than $\mathrm{L}_{2}$ [10]. Hence the error on $\mathrm{L}_{2}$ is more than on $\mathrm{L}_{1}$.

\section{AnAlysis Of Multipath ERror}

For any static GNSS base station, the multipath pattern of any SV is highly repeated with a constant phase shift during the successive days. When the SV is in the same position during each orbital pass, the multipath error is same. GPS satellites are semi synchronous, with a period of one half of a sidereal day. Ground track geometry of each SV at a reference station repeats with a fixed time shift of $236 \mathrm{~s}$ every day. This time shift is due to the difference between mean sun day and sidereal day [11]. Fig. 2 shows that the multipath error pattern (both on $\mathrm{L}_{1}$ and $\mathrm{L}_{2}$ ) is repeated for two successive days i.e., on $8^{\text {th }}$ and $9^{\text {th }}$ March, 2010 for SV 8.
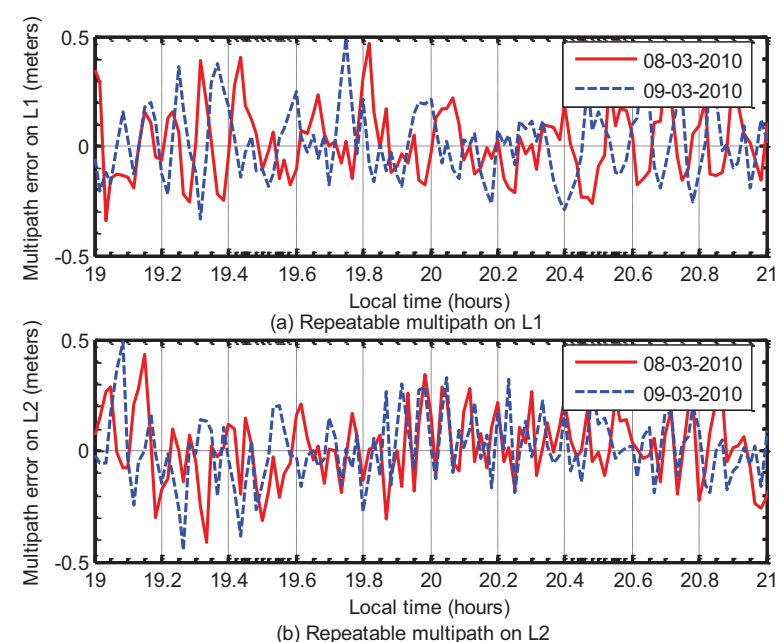

Figure 2. Repeatability of multipath pattern on $\mathrm{L}_{1}$ and $\mathrm{L}_{2}$ for SV8

Multipath is due to reflection of signals from physical surface. The multipath effects can be correlated with satellite elevation angle. Most of the obstructions produce reflected and / or diffracted signals with low elevations. Therefore, both real-time kinematic and static GNSS applications, multipath error is more at lower elevations, which is shown in Fig. 3.

\section{ANAlysis OF MUltipath ERror USING TEQC}

GPS data are recorded and stored as binary digits (bits) in the receiver (i.e., raw data). It is downloaded and converted to ASCII (American Standard Code for Information
Interchange) for exchange and archive. This conversion and other processing can be done by non-interactive TEQC software developed by UNAVCO (University Navstar Consortium), Colorado Springs. TEQC software can be used to Translate, Edit and Quality check (TEQC) of GPS raw data. It can take any of the Receiver Independent Exchange (RINEX) files such as Observation, Navigation and Meteorological files as input and can process them. It can handle RINEX version 1.0 and 2.0 files.
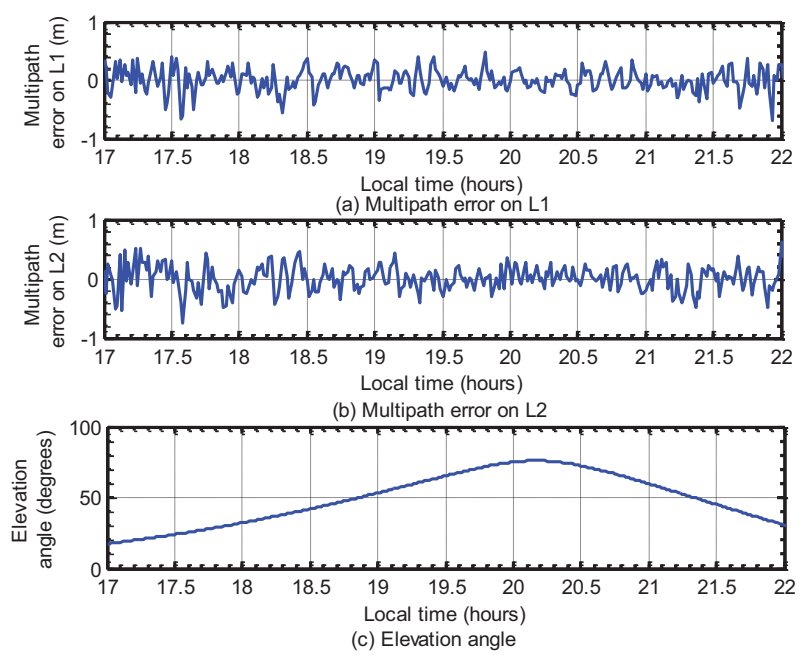

Figure 3. Multipath error dependency on elevation angle (SV 8)

For many common GPS native receiver formats, the TEQC, a freeware program allows the user to translate from the binary receiver format to the standard RINEX format and to quality-check the data before post processing. The TEQC software is widely used by many universities and agencies around the globe for generating RINEX files from GPS data collected during survey or by continuously operating stations [12], [13]. For Quality check of GPS data, a set of RINEX observation and navigation files are used namely "080310.10O", "08030660.10N" of dated 8 March 2010, which is acquired from a dual frequency GPS receiver (Model: Novatel DL 4 plus) located at NERTU, OU, Hyderabad. The navigation and observation files obtained from the receiver are quality checked with TEQC software using $q c$ lite mode and $q c$ full mode commands and further processed as shown in Fig. 4.

The multipath and SNR report files are important to assess the site specific (environmental and instrumental) errors that have repercussions on the accuracy of site position. In some scenarios, where GPS antennas are installed on building rooftops the multipath needs to be detected so that it is not mistaken for building or antenna phase center variations due to local vibrations, wind or even sharp temperature changes [11]. Identification of which satellite(s) is/are causing the multipath is an important assignment for understanding of their geometry at GPS receiver site. Identification of which satellite(s) is/are causing the multipath is an important assignment for understanding of their geometry at GPS receiver site. 


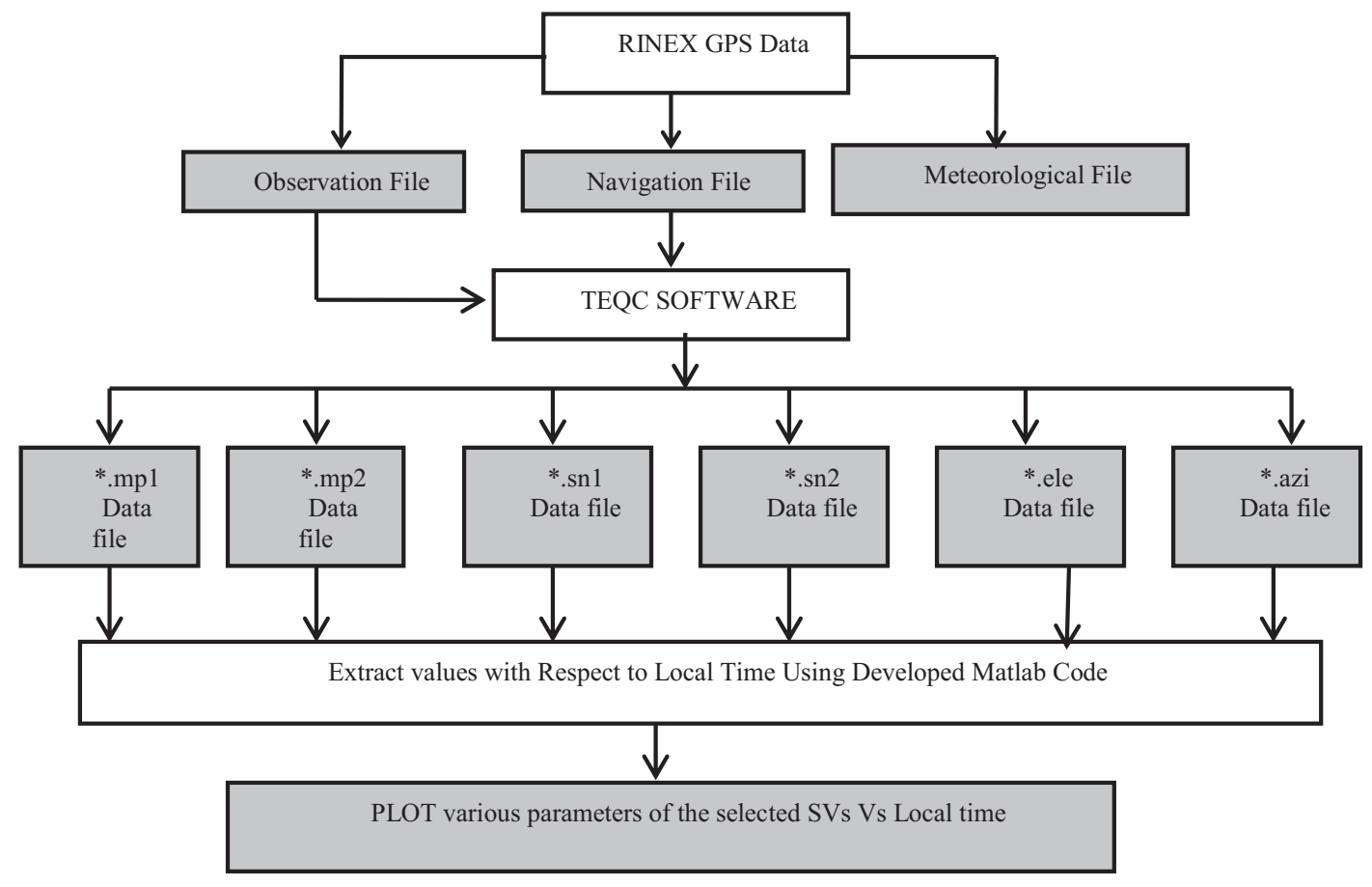

Figure 4. Multipath analysis using TEQC processed files

The GPS antenna at this station (NERTU) is located on a concrete pillar on the terrace of the building. This site is surrounded by Department of ECE building and vegetation. Multipath error variations are caused by a variety of factors such as buildings, nearby reflectors, antenna phase center variations and antenna pole movements etc. Hence, it is important to detect and separate multipath error to precisely estimate the receiver position at this site. The RINEX observation file "090310.10O" and navigation file "09030660.10N" ( $9^{\text {th }}$ March 2010) is applied to noninteractive post processing TEQC software. The Quality check process generates six report files corresponding to the multipath error (mp1 and mp2), SNR (sn1 and sn2), elevation and azimuth angle files. The GPS receiver antenna position is calculated by using QC, which matches with the pre-surveyed position of the site (Table I). The processed QC files are used to compute Root Mean Square (RMS) multipath error on $\mathrm{L}_{1}$ and $\mathrm{L}_{2}$ carrier frequencies. The RMS multipath error obtained from QC results is summarized in Table II. The errors are less than a meter. Fig. 5 shows $\mathrm{L}_{1}$ and $\mathrm{L}_{2}$ pseudorange (code) multipath error (in meters) for SV 6 (9 March 2010) during 13:00:00 to 17:00:00 hours. The analysis has been carried out with an elevation mask of $10^{0}$ to avoid higher multipath oscillations at lower elevations. Here, the data are recorded at $60 \mathrm{sec}$ intervals. From Fig. 5, it is observed that multipath error (mean) on $\mathrm{L}_{1}$ carrier frequency is $0.0148 \mathrm{~m}$ where as on $\mathrm{L}_{2}$, it is $0.0273 \mathrm{~m}$. This shows that multipath error on $\mathrm{L}_{2}$ carrier frequency is more than on $\mathrm{L}_{1}$ (Table III).

Fig. 6 shows the Signal to Noise Density Ratio (SNR) variations on $L_{1}$ and $L_{2}$ carrier frequencies. The peak value of SNR on $\mathrm{L}_{1}$ is $47 \mathrm{~dB}-\mathrm{Hz}$ where as on $\mathrm{L}_{2}$, it is $41 \mathrm{~dB}-\mathrm{Hz}$ during the local time 15:00:00 to 15:50:00 hours. The SNR on $\mathrm{L}_{1}$ is more than $\mathrm{L}_{2}$ which is clearly given in Table III. Fig. 7 shows the corresponding elevation and azimuth angles of SV 6. For better understanding of multipath geometry, the three plots namely multipath error (m), SNR
$(\mathrm{dB}-\mathrm{Hz})$ and their elevation angle are compared. From Figs 5, 6 and 7, it is observed that the SNR and elevation angles are directly proportional, whereas SNR and multipath error are inversely proportional. It is also observed that, for a peak value of elevation angle $\left(37^{\circ}\right)$ attains maximum SNR values of $46 \mathrm{~dB}-\mathrm{Hz}$ on $\mathrm{L}_{1}$ and $40.7097 \mathrm{~dB}-\mathrm{Hz}$ on $\mathrm{L}_{2}$. At this elevation angle value, the multipath error reaches minimum value $\left(0.0454 \mathrm{~m}\right.$ on $\mathrm{L}_{1}$ and $0.0573 \mathrm{~m}$ on $\left.\mathrm{L}_{2}\right)$ during local time 15:00:00 to $15: 50: 00$ hours.

TABLE I.

NERTU RECEIVER ANTENNA POSITION (WGS-84)

\begin{tabular}{|c|r|}
\hline $\begin{array}{l}\text { Coordi } \\
\text { nate }\end{array}$ & \multicolumn{1}{c|}{$\begin{array}{c}\text { Value of the } \\
\text { parameter }\end{array}$} \\
\hline $\mathrm{X}(\mathrm{m})$ & 1211896.6729 \\
\hline $\mathrm{Y}(\mathrm{m})$ & 5966440.3357 \\
\hline $\mathrm{Z}(\mathrm{m})$ & 1896110.0680 \\
\hline$\Phi(\mathrm{deg})$ & 17.408037 \\
\hline$\lambda(\mathrm{deg})$ & 78.518345 \\
\hline $\mathrm{h}(\mathrm{m})$ & 465.1588 \\
\hline
\end{tabular}

TABLE II.

SUMMARY OF MULTIPATH ERROR

\begin{tabular}{|c|l|c|}
\hline \multicolumn{1}{|c}{$\begin{array}{c}\text { Carrier } \\
\text { Measurement }\end{array}$} & L1 & $0.325264(\mathrm{~m})$ \\
\cline { 2 - 3 } & L2 & $0.402367(\mathrm{~m})$ \\
\hline $\begin{array}{c}\text { Code } \\
\text { Measurement }\end{array}$ & P1 & $0.50(\mathrm{~m})$ \\
\cline { 2 - 3 } & $\mathbf{P 2}$ & $0.65(\mathrm{~m})$ \\
\hline
\end{tabular}


TABLE III.

MEAN AND STANDARD DEVIATION OF MULTIPATH ERROR (M) AND SIGNAL TO NOISE DENSITY RATIO (dB-HZ)

\begin{tabular}{|l|l|l|l|l|l|}
\hline \multirow{2}{*}{$\begin{array}{l}\text { No } \\
\text { No }\end{array}$} & Parameter & \multicolumn{2}{|l|}{$\mathbf{L}_{1}$ carrier } & \multicolumn{2}{l|}{$\mathbf{L}_{2}$ carrier } \\
\cline { 2 - 6 } & Mean & Std & Mean & Std \\
\hline 1. & Multipath error (m) & 0.0148 & 0.2343 & 0.0273 & 0.3005 \\
\hline 2. & $\begin{array}{l}\text { Signal to noise } \\
\text { density ratio } \\
\text { (dB-Hz) }\end{array}$ & 43.7214 & 2.3799 & 37.7679 & 2.7435 \\
\hline
\end{tabular}

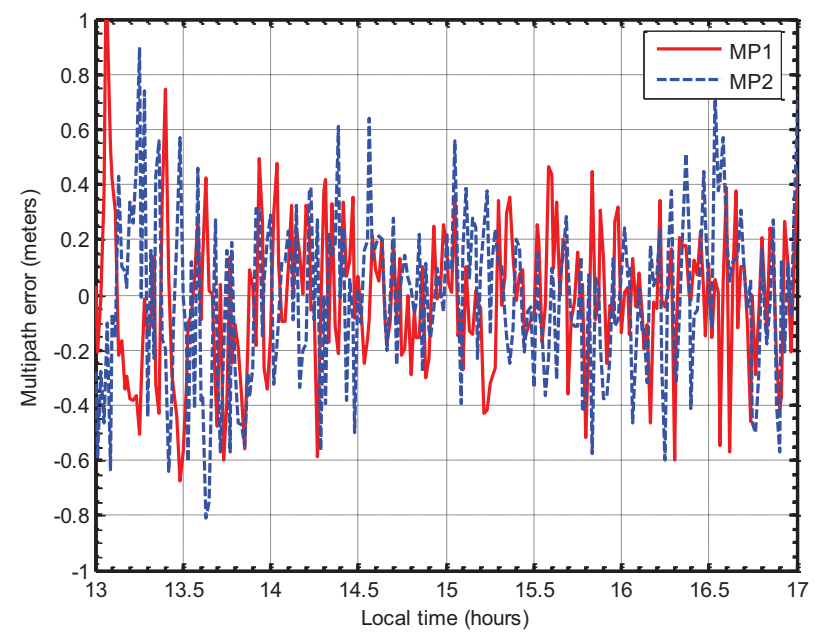

Figure 5. Multipath error (m) on $\mathrm{L}_{1}$ and $\mathrm{L}_{2}$ for $\mathrm{SV} 6$

At lower elevation angles (say $15^{\circ}$ ) SNR attains minimum value $\left(38.2 \mathrm{~dB}-\mathrm{Hz}\right.$ on $\mathrm{L}_{1}$ and $32.5 \mathrm{~dB}-\mathrm{Hz}$ on $\left.\mathrm{L}_{2}\right)$ whereas, the multipath error attains a maximum value $(0.0687 \mathrm{~m}$ on $\mathrm{L}_{1}$ and $0.3017 \mathrm{~m}$ on $\mathrm{L}_{2}$ ). The results show that multipath error is more at lower elevations and less at higher elevations because the satellite signal at lower elevations enters the antenna at a point where the gain is relatively low, and the reflected signals enter the antenna where the gain is relatively high. Therefore, the multipath effect at low elevation angles can be reduced by setting an elevation mask to the receiver.

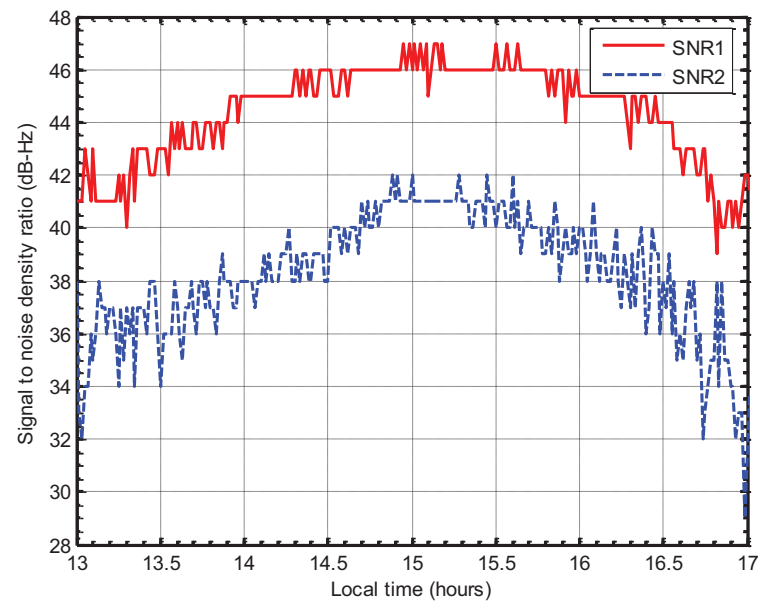

Figure 6. Signal to noise density ratio $(\mathrm{dB}-\mathrm{Hz})$ on $\mathrm{L}_{1}$ and $\mathrm{L}_{2}$ for $\mathrm{SV} 6$
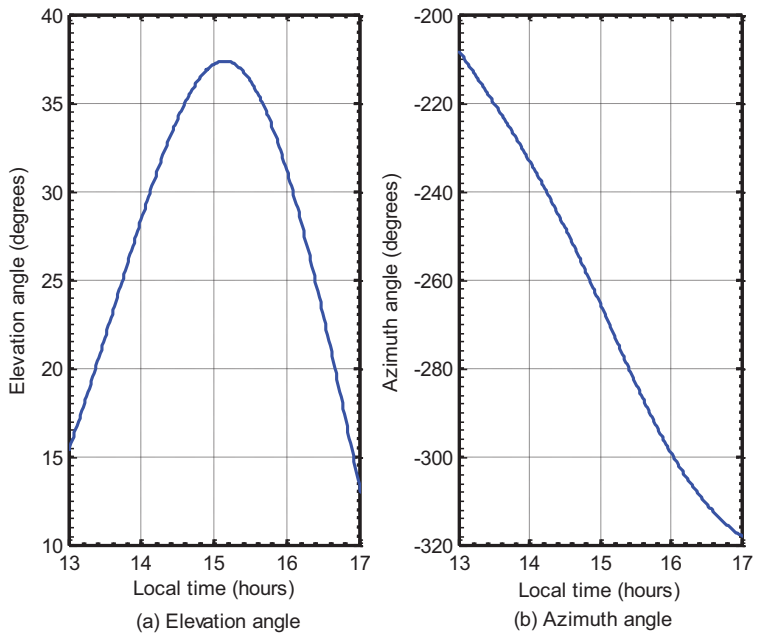

Figure 7. Elevation and Azimuth angle (degrees) variations for SV 6

\section{Conclusions}

In this paper, the multipath error (time series) on both $\mathrm{L}_{1}$ and $\mathrm{L}_{2}$ is precisely estimated by a prominent method known as $\mathrm{CMC}$ technique. The multipath errors (mean) estimated with experimental GPS data on $\mathrm{L}_{1}$ and $\mathrm{L}_{2}$ are $0.79 \mathrm{~m}$ and $2.01 \mathrm{~m}$ respectively. The CMC technique is very useful for both real-time kinematic and static applications. Various characteristics such as magnitude and repeatability of GNSS multipath plays a major role in installing base stations for DGPS and LAAS applications. The maximum carrier phase multipath error for $\mathrm{L}_{1}$ and $\mathrm{L}_{2}$ is $4.75 \mathrm{~cm}$ and $6.0 \mathrm{~cm}$ respectively. But, the maximum pseudorange (code) multipath error can reach up to (one chip wavelength) $293.05 \mathrm{~m}$ for the C/A-code and $29.305 \mathrm{~m}$ for P-code measurements. Therefore, the magnitude of multipath error is more on the pseudorange measurements than on the carrier phase measurements. For any static GNSS base station, the multipath pattern of any SV is highly repetitive with a constant phase (time) shift (approximately $236 \mathrm{~s}$ ) during the successive days. Hence by creating such multipath time series patterns for couple of days at the static station, multipath error can be predicted for the forthcoming days by shifting the time by $236 \mathrm{~s}$ for everyday.

\section{REFERENCES}

[1] Braasch M. S., Van Dierendonck A. J., "GPS receiver architectures and measurements", Proceedings of the IEEE, Vol. 87, No.1, January, 1999, pp: 48-64.

[2] Georgiadou Y., Kleusberg A., "On carrier signal multipath effects in relative GPS positioning", Manuscript Geodetics, 1988, Vol. 13, pp: 172-179.

[3] Hagerman L., "Effects of multipath on Coherent and Non coherent PRN Ranging Receiver", Aerospace Rep. TOR-0073 (3020-03)-3, Development Planning Division, the Aerospace Corporation, May 15, 1973.

[4] Braasch, M. S., "Multipath effects, in Global Positioning System: Theory and Applications", Vol. 1, edited by B. W. Parkinson et al., chap. 14, Am. Inst. of Aeronaut. And Astronaut., Reston, 1996.

[5] Satirapod, C. and Rizos, C., "Multipath mitigation by wavelet analysis for GPS base station applications," Survey Review. CASLE. London, Vol.38, pp.2-10, May 2005. 
[6] Bilich, A., and K. M. Larson, "Mapping the GPS multipath environment using the Signal-to-Noise Ratio (SNR)", Radio Science, Vol.42, RS6003, 2007.

[7] K Yedukondalu, A D Sarma, and V S Srinivas, "Estimation and Mitigation of GPS Multipath Interference using Adaptive Filtering", Progress in Electromagnetics Research M (PIERM), Vol. 21, pp: 133-148, 2011, USA, ISSN: 1937-8726.

[8] K Yedukondalu, A D Sarma, Ashwani Kumar and K Satyanarayana, "Spectral Analysis and Mitigation of GPS Multipath Error Using Digital Filtering for Static Applications", IETE Journal of Research, Vol. 59, Issue 2, March-April 2013, pp: 156-166, Medknow publishers, ISSN: 0377-2063.
[9] LinLin G E, Shaowei Han and Chris Rizos, "Multipath mitigation of continuous GPS measurements using an adaptive filter", GPS solutions, Vol. 4, No: 2, pp. 19-30, 2000.

[10] Kaplan D., "Understanding GPS: Principles and Applications", Artech House, Boston, London, 1996.

[11] Ogaja, C and C. Satirapod, "Analysis of high-frequency multipath in 1-Hz GPS kinematic solutions", GPS SolutionsSpringer Verlag, Vol.11, No.4, pp.269-280, 2007.

[12] Estey and Meertens, "TEQC: The multipurpose tool kit for GPS/GLONASS data”, Journal GPS Solutions, Vol. 3, No.1, pp. 42-49, 1999.

[13] Gurtner, W., "RINEX: The Receiver-Independent Exchange Format", GPS World, Volume 5, Number 7, pp.48-52, 2000. 